\title{
Protective immunity to Japanese encephalitis virus associated with anti-NS1 antibodies in a mouse model
}

\author{
Yize Li', Dorian Counor ${ }^{1}$, Peng Lu', Veasna Duong ${ }^{2}$, Yongxin $\mathrm{Yu}^{3}$ and Vincent Deubel ${ }^{1,4^{*}}$
}

\begin{abstract}
Background: Japanese encephalitis virus (JEV) is a major mosquito-borne pathogen that causes viral encephalitis throughout Asia. Vaccination with an inactive JEV particle or attenuated virus is an efficient preventative measure for controlling infection. Flavivirus NS1 protein is a glycoprotein secreted during viral replication that plays multiple roles in the viral life cycle and pathogenesis. Utilizing JEV NS1 as an antigen in viral vectors induces a limited protective immune response against infection. Previous studies using E. coli-expressed JEV NS1 to immunize mice induced protection against lethal challenge; however, the protection mechanism through cellular and humoral immune responses was not described.

Results: JEV NS1 was expressed in and purified from Drosophila S2 cells in a native glycosylated multimeric form, which induced T-cell and antibody responses in immunized C3H/HeN mice. Mice vaccinated with $1 \mu \mathrm{g}$ NS1 with or without water-in-oil adjuvant were partially protected against viral challenge and higher protection was observed in mice with higher antibody titers. IgG1 was preferentially elicited by an adjuvanted NS1 protein, whereas a larger load of IFN- $\gamma$ was produced in splenocytes from mice immunized with aqueous NS1. Mice that passively received anti-NS1 mouse polyclonal immune sera were protected, and this phenomenon was dose-dependent, whereas protection was low or delayed after the passive transfer of anti-NS1 MAbs.
\end{abstract}

Conclusion: The purified NS1 subunit induced protective immunity in relation with anti-NS1 IgG1 antibodies. NS1 protein efficiently stimulated Th1-cell proliferation and IFN- $\gamma$ production. Protection against lethal challenge was elicited by passive transfer of anti-NS1 antisera, suggesting that anti-NS1 antibodies play a substantial role in antiviral immunity

Keywords: Japanese encephalitis virus, T-cell response, Antibodies, Monoclonal antibodies, NS1 protein, Mouse model

\section{Introduction}

Japanese encephalitis virus (JEV) is one of the most important mosquito-borne viruses in East and Southeast Asia, where seasonal outbreaks cause more than 50,000 infections and 10,000 deaths annually [1]. JEV is a mosquito-borne flavivirus in the family Flaviviridae. The Flavivirus genus contains more than 70 viruses with positive-sense, single-stranded RNA genomes $(\sim 11 \mathrm{~kb})$

\footnotetext{
*Correspondence: vdeubel@pasteur-kh.org

'Key Laboratory of Molecular Virology and Immunology, Institut Pasteur of Shanghai, Shanghai Institutes for Biological Sciences, Chinese Academy of Sciences, Shanghai 20025, China

${ }^{4}$ Present address: Institut Pasteur in Cambodia, Phnom Penh, Cambodia Full list of author information is available at the end of the article
}

that encode a polypeptide ( 3400 amino acids) consisting of the capsid protein $C$ (core protein), the matrix protein (envelope protein $\mathrm{M}$ ), the major envelope protein $\mathrm{E}$, a number of small non-structural proteins (NS1, NS2A, NS2B, NS4A and NS4B), a helicase (NS3) and a RNA-directed polymerase (NS5) that are cleaved and co- or post-translationally processed by host- or virusspecific proteases [2]. The first non-structural protein (NS1) is translocated to the endoplasmic reticulum (ER) via signal sequences in a trans-membrane $\mathrm{C}$-terminal stretch of protein E, where it is involved in ERassociated RNA replication [3]. NS1 is N-glycosylated then secreted to the extracellular milieu [4]. The pathogenic role of NS1 remains largely unknown, but has

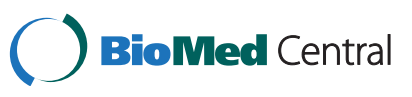


been shown to be associated with Factor $\mathrm{H}$ in West Nile virus (WNV) infection [5] and with C4b in WNV, yellow fever virus (YFV), and dengue virus (DENV) infections, where it may modulate complement activation [6,7]. NS1 may use structural mimicry similar to those found in the endothelial membrane or coagulation factors, which may elicit the autoimmunity that is deleterious in DENV hemorrhagic fever $[8,9]$. However, no such autoantibody has yet been found in JEV infection [10]. Its association with phospholipids may induce vascular homeostasis in DENV hemorrhagic fever, which is similar to that induced by plasma lipoproteins [4].

Prevention of Japanese encephalitis through vaccination was shown to be efficient when using either a formalin-inactivated virus produced in mouse brain or cell culture, or a live attenuated vaccine, SA14-14-2 [11], which was developed in China and is broadly used for childhood vaccination in mainland China, India, and several other Southeast Asian countries [12]. The SA1414-2 virus is produced in hamster primary kidney cells and is widely used in vaccination programs because of its innocuity, efficiency, and low cost to developing countries. A JEV vaccine approved by the Food and Drug Administration was recently produced in Vero cells, which was purified from SA14-14-2-infected cell supernatants and inactivated formalin [11].

The immunogenicity and protective immunity of flavivirus NS1 has been studied using various vaccine types. Animals were either immunized with YFV NS1 [13], or infected with vaccinia viruses or adenoviruses expressing recombinant NS1 from DENV [14], YFV [15], tick-borne encephalitis virus (TBEV) [16,17], or WNV [18]. However, they showed variable protective immune responses. Vaccinations with flavivirus NS1 DNA were also tested in NS1-induced immune protection studies against DENV [19] and TBEV [20]. These studies showed that the NS1 contributes to the induction of protective immunity against flaviviral infections. The anti-NS1 protection mechanism was partially determined, showing that passive transfer of anti-YFV NS1 monoclonal antibodies (MAbs) protected mice or reduced their neuropathology after YFV challenge [21,22] and that WNV anti-NS1 MAbs protected mice from lethal challenge [23,24].

Mice immunized with JEV NS1 expressed in insect cells induced low protection [25]. Recombinant viruses or DNA vaccines expressing JEV E or NS1 genes were used to vaccinate mice, which resulted in differing levels of protection [26]. The value of using a vaccine containing the native hexameric form of a purified flavivirus NS1 glycoprotein to protect against lethal viral challenges has yet to be tested in mice. One obstacle in protection studies is that mice are less susceptible to a viral challenge by the time a vaccination schedule in immunocompetent mice is achieved. A possible surrogate for testing protective efficacy is the use of adoptive immunity by injecting flavivirus anti-NS1 antibodies into young mice $[14,17,22]$.

A JEV NS1 protein purified from a Drosophila S2 established cell line supernatant [27] was used to immunize $\mathrm{C} 3 \mathrm{H} / \mathrm{HeN}(\mathrm{C} 3 \mathrm{H})$ mice and to test the induction of cellular and humoral immunity. Protection of mice by antibodies elicited against NS1 was tested by JEV infection of mice that were actively or passively immunized. Our results support the role of anti-NS1 antibodies in protection against flaviviral infection.

\section{Results}

\section{Characterization of the NS1 immunogen}

In a previous study, we successfully produced and purified large amounts of extracellular hexameric forms of JEV NS1 protein [27]. We studied the processing and composition of carbohydrates of NS1 protein produced in the supernatant of Drosophila S2 cells. Heat-denatured NS1 was mock-treated or treated with Endo $\mathrm{H}$ (Endoglycosidase $\mathrm{H}$ ) or PNGase F (Peptide: N-Glycosidase F). Endo H and PNGase $F$ treatment reduced the molecular weight of extracellular NS1, by 2 kD (Additional file 1: Figure S1A), indicating that the protein acquired glycans in the secretory pathway of Drosophila cells. The type of glycans was identified by lectin affinity. The NS1 protein was recognized by GNA (Galanthus nivalis agglutinin) which recognizes terminal mannose, and DSA (Datura stramonium agglutinin) which recognizes Gal-(1-4)N-Acetylglucosamine (GlcNAc) in complex and hybrid N-glycans, respectively (Additional file 1: Figure $\mathrm{S} 1 \mathrm{~B}$ ), but not by SNA (Sambucus nigra agglutinin) which recognizes sialic acid linked (2-6) to galactose and MAA (Maackia amurensis agglutinin) which recognizes sialic acid linked (2-3) to galactose (data not shown). These results indicated that the glycoprotein NS1 contained N-glycans with Gal-(1-4) GlcNAc and a terminal mannose, but apparently not sialic acid.

\section{Mouse immune responses to NS1 and SA14-14-2 immunization}

Four-week-old $\mathrm{C} 3 \mathrm{H}$ mice were immunized twice four weeks apart using a purified NS1 hexamer obtained from Drosophila S2 cell line supernatants [27], either alone (aqueous) or adjuvanted with water-in-oil ISA-51-VG. Serum samples from each group were tested individually by anti-NS1 antibody titration. NS1 immunization induced anti-NS1 antibody responses in both groups of mice and the use of an adjuvant significantly increased the antibody titer $(p<0.005)$ (Figure 1). Six mouse sera samples from each group were pooled to test IgG1 and IgG2a antibodies against NS1. Immunization with aqueous or adjuvanted NS1 protein induced both IgG1 and IgG2a antibody responses, with an IgG1 titer four to nine times higher 


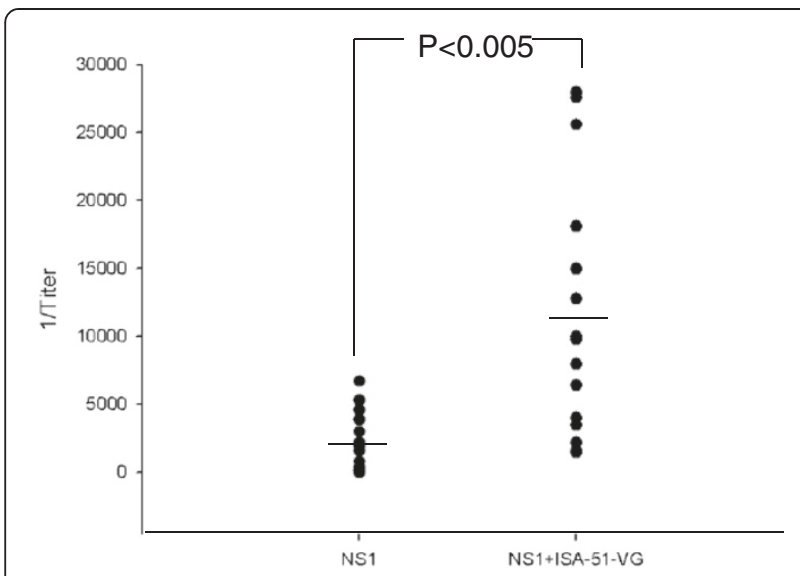

Figure $1 \mathrm{lgG}$ antibody response of mice immunized with aqueous and adjuvanted NS1. Four-week-old C3H mice were immunized with $1 \mu \mathrm{g}$ of purified NS1. Two weeks after a second immunization was given at two months of age, mouse sera were sampled and the lgG titers were tested by indirect ELISA. The data for immunization with recombinant NS1 are derived from two independent experiments. Antibodies of 18 mice sera were titrated for each group and analyzed by Student's t-test.

than that of IgG2a, but a similar titer to IgG2a (Table 1). SA14-14-2 vaccination mainly induced anti-NS1 IgG2a antibodies. The proliferation of T-cells and IFN- $\gamma$ secretion by splenic cells of immunized $\mathrm{C} 3 \mathrm{H}$ mice in response to stimulation with purified JEV NS1 protein were tested. The T-cell proliferation stimulation index (SI) of the PBS group was 1, while those of the aqueous NS1 and adjuvanted NS1 groups were 1.59 and 1.51, respectively, and these were both significantly higher $(p<0.05)$ than the SI of the phosphate buffered saline (PBS) group (Figure 2A). After vaccination with SA14-14-2 or Dulbecco's modified Eagle's medium (DMEM), purified NS1 was used for splenic cell stimulation in vitro. The T-cell proliferation SI of SA14-14-2 was 2.42, significantly higher than the control group $(\mathrm{SI}=1.88 ; p<0.05)$ (Figure $2 \mathrm{~A})$. IFN- $\gamma$ production by splenic cells was quantified over a period of five days. IFN- $\gamma$ was detected on day 2 or 3 post-stimulation in the splenocyte culture supernatants of mice immunized with aqueous or adjuvanted NS1, SA14-14-2 and complete

Table 1 Determination of antibodies titers and seroneutralization of pooled sera from immunized mice

\begin{tabular}{|c|c|c|c|c|c|c|c|c|}
\hline \multirow[t]{3}{*}{ Immunogen } & \multicolumn{6}{|c|}{ Antibodies Titration } & \multirow{2}{*}{\multicolumn{2}{|c|}{$\begin{array}{l}\text { Sero- } \\
\text { neutralization }\end{array}$}} \\
\hline & \multicolumn{2}{|l|}{$\lg G$} & \multicolumn{2}{|l|}{$\lg G 1$} & \multicolumn{2}{|l|}{$\lg G 2 a$} & & \\
\hline & Before $^{a}$ & After $^{b}$ & Before & After & Before & After & Before & After \\
\hline NS1 & 5000 & 6400 & 5000 & 5000 & 1200 & 3000 & 0 & 40 \\
\hline NS1 + adjuvant & t 15000 & 18000 & 15000 & 15000 & 1600 & 3200 & 0 & 40 \\
\hline SA14-14-2 & 1200 & 1000 & 300 & 0 & 2400 & 2400 & 80 & 80 \\
\hline PBS & 0 & 600 & 0 & 0 & 0 & 2400 & 0 & 40 \\
\hline
\end{tabular}

a Sera collected two weeks after $2^{\text {nd }}$ boost and two weeks before challenge.

${ }^{b}$ Sera collected four weeks after challenge.
DMEM. The highest IFN- $\gamma$ load was $3 \mathrm{ng} \mathrm{ml}^{-1}$ in the aqueous NS1 group, $1 \mathrm{ng} \mathrm{ml}^{-1}$ in the adjuvanted NS1 group, $1.5 \mathrm{ng} \mathrm{ml}^{-1}$ in the SA14-14-2 group and $150 \mathrm{pg} \mathrm{ml}^{-1}$ in the complete DMEM group on day 5 poststimulation (Figure $2 \mathrm{~B}$ ).

\section{NS1 immunization induced immune responses that partially protected mice from viral challenge}

To determine whether the anti-NS1 immunity observed in immunized mice was protective, mice were challenged by an intranasal (i.n.) injection of $10^{4}$ pfu of JEV SA14 and mortality was recorded over four weeks. This virus dose corresponded to 100 times the lowest dose killing the largest number of mice (Additional file 2: Figure S2B). Mouse challenge by i.n. was chosen rather than i.p. because the number of deaths and the time before death were more consistent (Additional file 2: Figure S2A). The survival rate of the adjuvanted NS1 group was significantly higher $(83 \%)$ when compared with a negative control group (injection with PBS) that had a $50 \%$ survival rate $(p<0.05)$ (Figure 3, Table 2$)$. The survival rate of the aqueous NS1 group was $72 \%$, but the difference from the survival rate of the negative control group was not significant $(p>0.05)$ (Table 2), although a delay in the time of death was observed in the aqueous NS1immunized mice when compared with the PBS mockimmunized mice (Figure 3).

Sera of mice that had survived the SA14 virus challenge were titrated by ELISA. SA14 infection did not increase the anti-NS1 IgG2a titers in the SA14-14-2 -vaccinated group, and anti-NS1 IgG1 was not detected after the challenge. In contrast, SA14 challenge induced an IgG2a antibody titer increase, but not IgG1, in the aqueous or adjuvanted NS1 groups (Table 1). Mouse sera collected before and after challenge were also tested for seroneutralization to follow seroconversion. Sera from mice immunized with NS1 reached a TCID $_{50}$ titer of 40 after the challenge. Sera from the SA14-14-2 group exhibited the same neutralization titer $\left(\mathrm{TCID}_{50}\right.$ titer $=$ 80 ) before and after the challenge (Table 1). These data suggest that the attenuated virus vaccine, but not NS1, induced a sterilizing immunity against JEV.

In a previous experiment, sera from mice were pooled for antibody subtyping and neutralization testing. In order to verify whether there was any correlation between anti-NS1 antibody titer elicited by vaccination with NS1 and challenge protection, ELISA titers of 18 mice were calculated individually before challenge. Table 3 shows that the total number of surviving aqueous NS1-vaccinated mice (66.7\%) was not significantly higher than those receiving PBS (44.4\%) ( $\mathrm{p}=0.41)$; whereas all mice that had anti-NS1 antibody titers $\geq$ 2400 were all protected $(\mathrm{p}=0.008)$ compared to mice that had titers $<2400$ were not protected (33.3\%) 


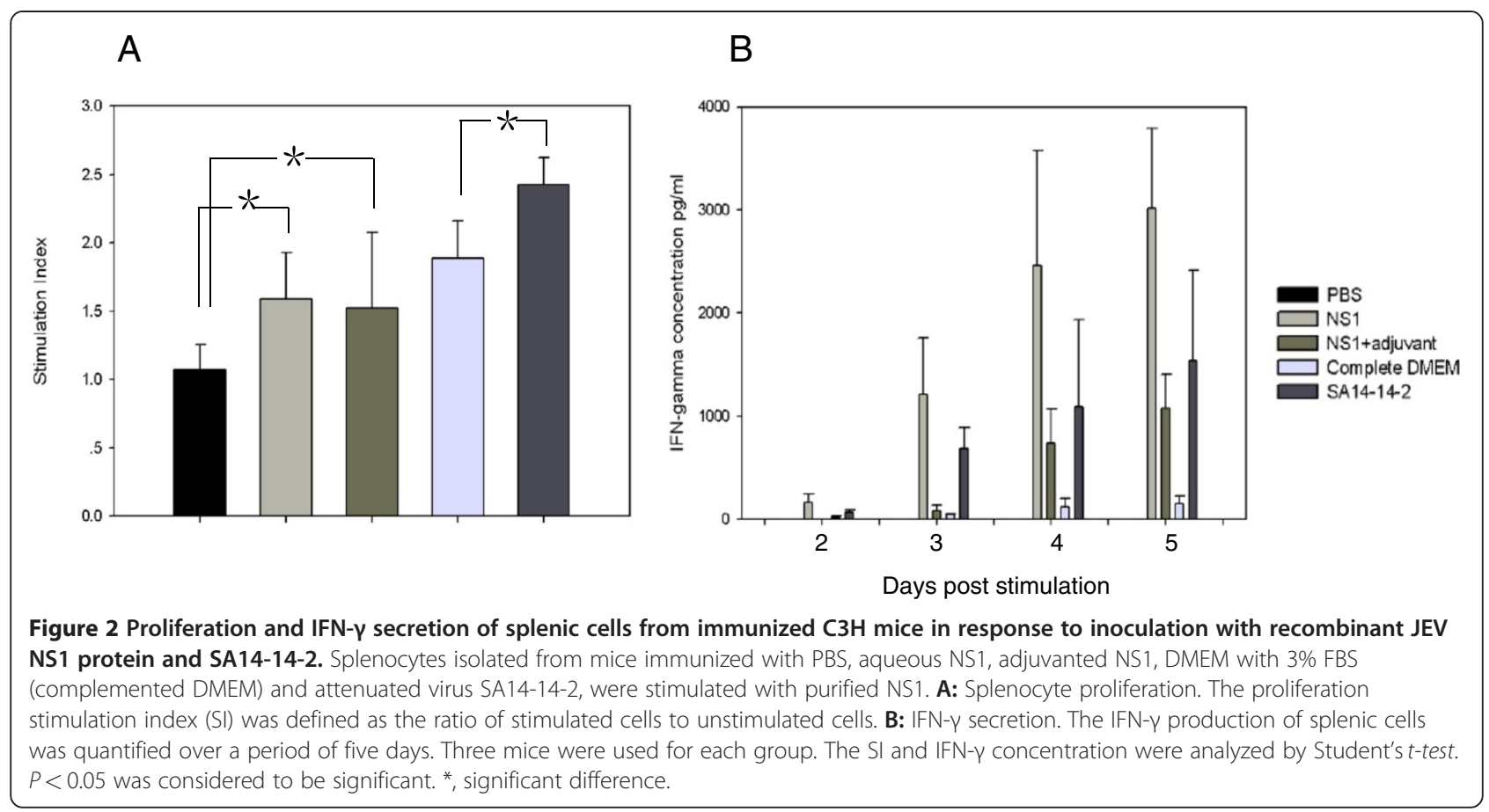

compared to the control $(44.4 \%)(p=1)$. This result suggests a relationship between anti-NS1 antibody titer and protective immunity against i.n. JEV challenge.

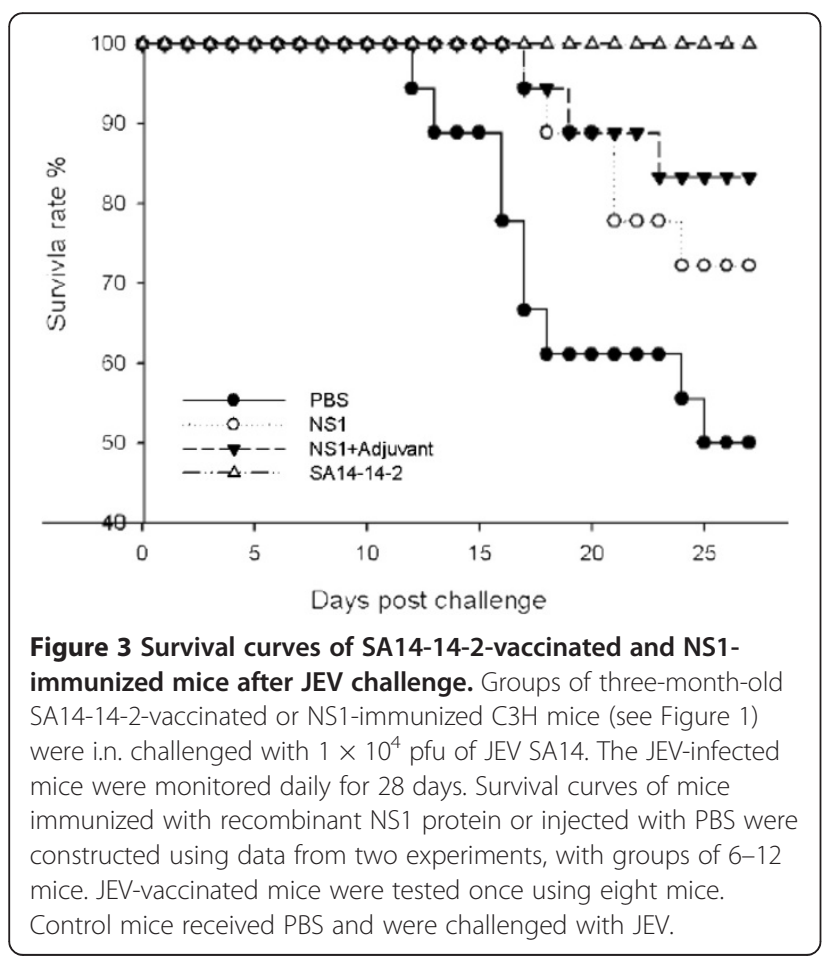

\section{Passive protection of mice by anti-NS1 antibodies}

We previously calculated that 20 pfu of JEV SA14 virus could kill $100 \%$ of four-week-old i.p.-infected C3H mice [28] as shown in Additional file 2: figure S2C.

To determine whether the protection of immunized mice was associated with an anti-NS1 antibody response, the sera from NS1-immunized mice with high titers of anti-NS1 antibodies (>1:3000) were collected and pooled to perform passive transfer tests. One hundred $\mu \mathrm{l}$ of NS1 mouse anti-sera injected $1 \mathrm{~h}$ prior to challenge provided $100 \%$ protection in challenged mice, but decreasing the dose to $30 \mu \mathrm{l}$ and $10 \mu \mathrm{l}$ provided 33\% and no protection, respectively (Figure 4 ). While sera from SA14-14-2-vaccinated mice conferred 100\% protection, all mice died that were injected with sera from PBS mock-immunized mice (Figure 4).

\section{Characterization of a panel of MAbs against NS1, for passive protection}

Eighteen MAbs against NS1 were generated in a previous study [27] and five had high affinity for NS1 (3E10, $4 \mathrm{C} 4,7 \mathrm{C} 2,7 \mathrm{H} 5$ and $8 \mathrm{~F} 1$ ), where they recognized cell surface-associated and intracellular NS1 (Table 4). MAb $4 \mathrm{C} 4$ recognized the N-terminus of NS1; MAb 3E10 detected NS1 in an ELISA and IFA, but not in a Western blot, indicating a probable recognition of a conformational epitope. Three MAbs recognized the C-terminus of the protein and cross-reacted with the DENV NS1 protein (Table 4). These five MAbs were purified and quantified before being passively transferred at doses of 
Table 2 Survival rate of C3H mice immunized with NS1 and SA14-14-2

\begin{tabular}{lll}
\hline Immunogen & No. of Survival mice/ No. of Immunized mice (survival rate) & $\boldsymbol{p}^{\mathbf{a}}$ \\
\hline NS1 & $13 / 18(72 \%)$ & 0.195 \\
NS1 + adjuvant & $15 / 18(83 \%)$ & 0.024 \\
SA14-14-2 & $8 / 8(100 \%)$ & 0.021 \\
PBS & $9 / 18(50 \%)$ & \\
\hline
\end{tabular}

a $P$ value was obtained by log rank test when comparing the survival curve of each group of vaccinated mice with PBS group.

$100 \mu \mathrm{g}$ or $500 \mu \mathrm{g}$ to four-week-old mice. Mice were challenged with 20 pfu of SA14 virus 1 h after MAb injection and mortality was recorded for four weeks. Mouse survival rates after passive transfer of $100 \mu \mathrm{g}$ of MAb 3E10, 4C4, and $7 \mathrm{C} 2$ were $16 \%, 33 \%$, and $8 \%$, respectively, whereas no mice survived after injection with MAbs $7 \mathrm{H} 5$ or $8 \mathrm{~F} 1$, or with the anti-HIV antibody used as a control (Figure 5, Table 5). However, increasing 7C2, 7H5, and 8F1 MAbs dosages to $500 \mu \mathrm{g}$ per mouse enhanced the survival period (Figure 5, Table 5). Calculation of the $x^{2}$ for the survival rate, the delay until mortality, and the dose of antibody indicated a significant anti-viral activity with these MAbs $(p<0.05)$ (Table 5).

\section{Discussion}

Japanese encephalitis remains a serious public health threat in Asia, where more than two billion people are at risk. The complex JEV zoonotic cycle prevents any direct action to reduce viral transmission; therefore, human infection can only be prevented by vaccination campaigns with children [12]. Apart from the liveattenuated JEV vaccine SA14-14-2 developed for childhood application [11], no affordable JEV vaccine is recognized for mass vaccination. Several vaccine candidates inducing neutralizing antibodies are under clinical trial and they may meet the immunogenicity and protective capacity requirements after a single dose regimen [11]. However, the use of NS1 protein as an immunogen to reinforce the immune response to JEV structural proteins has been discussed, although the induction mechanisms of protective JEV immunity using a NS1 hexameric antigen form have not been investigated. Drosophila S2 cells have been used for JEV NS1 protein expression and purification from the cell supernatant harvested after serum-free cell culture [27]. Previous recovery of DENV E protein crystals in S2 cells indicated that this system expressed native-like and well-folded glycoproteins [29]. More than $50 \mathrm{mg} \mathrm{L}^{-1}$ of the hexameric form of NS1 glycosylated protein were expressed in the cell culture supernatant [27], which was shown in this study to contain carbohydrates similar to the native protein produced in infected cells [30] and was suitable for recombinant vaccine subunit preparation. In this study, two doses of $1 \mu \mathrm{g}$ of glycosylated hexameric JEV NS1 were used to immunize mice. High antibody titers were detected in the sera of two groups of mice immunized with aqueous or emulsified NS1 with ISA-51-VG formulations. The adjuvant ISA-51-VG was a mix of mineral oil and a surfactant, which has been previously tested for human vaccination [31]. This adjuvant was tested for its capacity to boost the T-cell response against NS1 in immunized mice. The titers of IgG1 subclass were 4-9 times higher than those of IgG2a in both groups of mice, while titers of IgG1 in mice immunized with adjuvanted NS1 were 2-4 times higher when compared with those of mice immunized with aqueous NS1, whereas IgG2a titers remained low. Similarly, 100 times higher IgG1 titers compared with IgG2a were observed in mice that were immunized with $E$. coli-expressed JEV NS1 protein mixed with Freund's adjuvant [32]. This difference was presumably due to the use of Freund's adjuvant, the high antigen dose and the number of antigen injections (three instead of two). In vitro splenocyte stimulation by NS1 elicited T-cell proliferation and IFN$\gamma$ secretion, although higher IFN- $\gamma$ secretion was observed in mice immunized with aqueous NS1. These results suggested that the NS1 proteins are engulfed by antigen presenting cells (APCs) in vivo. The peptides derived from NS1 digestion are subsequently presented by $\mathrm{MHC}$ class II molecules to T helper cells. The IgG1

Table 3 Survival rate of three month-old C3H mice immunized with NS1 or PBS

\begin{tabular}{llll}
\hline Immunogen & Anti-NS1 IgG antibody titer range $^{\mathbf{a}}$ & No. of Survival mice/No. of Immunized mice (Survival rate) $^{P^{\mathbf{b}}}$ \\
\hline NS1 & $0-12800$ & $12 / 18(66.7 \%)$ & 0.41 \\
NS1 & $0-2400$ & $3 / 9(33.3 \%)$ & 1 \\
NS1 & $2400-12800$ & $9 / 9(100 \%)$ & 0.008 \\
PBS & 0 & $4 / 9(44.4 \%)$ & \\
\hline
\end{tabular}

a Two weeks before challenge, mouse sera were collected for anti-NS1 lgG antibody titration. The NS1-immunized group of mice (18 mice in total) was divided into two groups according to anti-NS1 IgG titers: one group with anti-NS1 IgG $<2400$ (9 mice) and one group with anti-NS1 IgG $>2400$ (9 mice).

${ }^{\mathrm{b}} P$ value was obtained by log rank test when comparing the survival curve of each group with PBS group. 


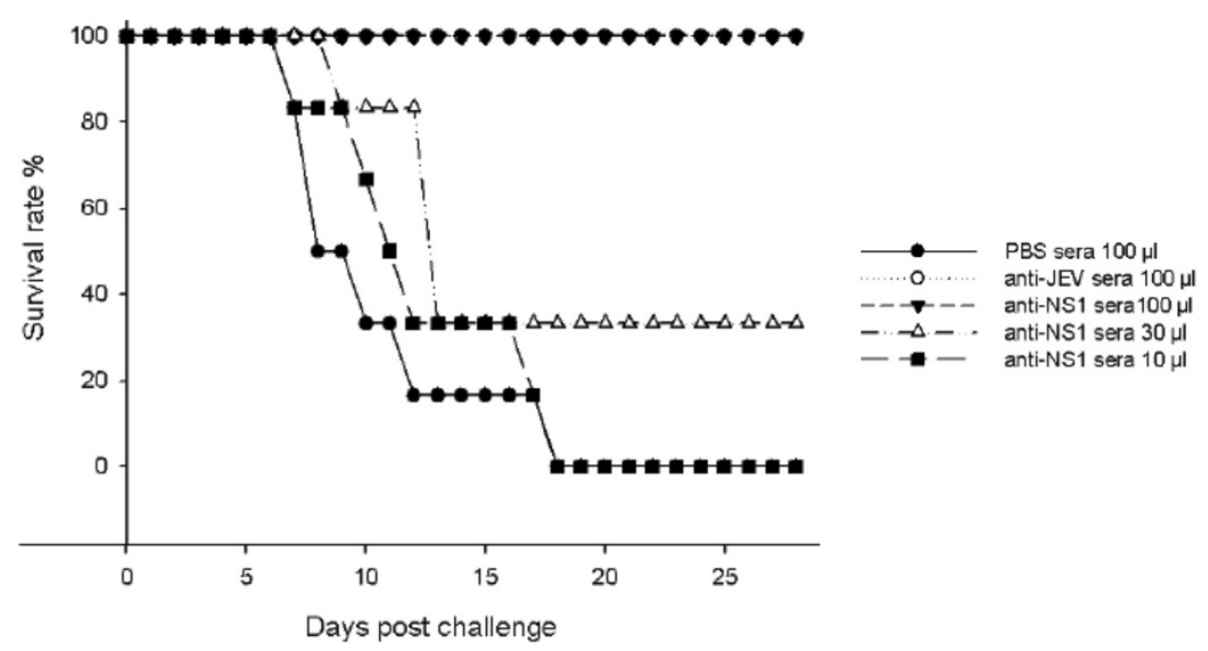

Figure 4 Survival of mice passively injected with anti-NS1 antisera and challenged with JEV. Groups of four-week-old C3H mice were administered with $100 \mu \mathrm{l}, 30 \mu \mathrm{l}$ and $10 \mu \mathrm{l}$ of anti-NS1 mouse antisera, or $100 \mu \mathrm{l}$ sera from PBS-injected mice (negative control) or $100 \mu \mathrm{l}$ of antiSA14-14-2 antisera (anti-JEV), and infected $1 \mathrm{hr}$ later with 20 pfu of JEV SA14. The JEV infected mice were monitored daily for 28 days. The survival curve was constructed using data from one (100 $\mu \mathrm{l}$ anti-JEV, 30 and $10 \mu \mathrm{l}$ of anti-NS1 antisera), two (sera from PBS-injected mice) or three (100 $\mu \mathrm{l}$ of anti-NS1 antisera) experiments. For $100 \mu \mathrm{l}$ anti-JEV antisera group, 30 and $10 \mu \mathrm{l}$ of anti-NS1 antisera groups, sera from PBS-injected mice group, 6 mice were used for each experiments. Six to 12 mice were used for $100 \mu$ lanti-NS1 antisera groups of each experiment.

subclass antibody response corresponds to Th2 cell activation, whereas the IgG2a response reflects Th1 cell activation. The IFN- $\gamma$ produced by Th1 cells inhibits Th2 cell proliferation and IgG1 production [30]. These results indicate that NS1 immunization elicited both Th1 and Th2 cell responses and that ISA-51-VG improved IgG1 production, and reduced Th1 activation and INF- $\gamma$ expression. Mice inoculated with TBE NS1, which was expressed by a recombinant adenovirus, stimulated in vivo IFN- $\gamma$ production [17]. A previous study showed that soluble DENV-1 NS1 is a lipoprotein [4] and was internalized by mouse hepatocytes in vivo and by cultured cell lines in vitro [33]. We observed that purified soluble JEV NS1 attached to many types of cell membranes in vitro and was subsequently internalized (Li and Deubel, unpublished data). This feature may at least partially explain why aqueous NS1 rapidly stimulated the Th1 cell response via APCs, whereas NS1 mixed with ISA-51-VG was slowly released from the emulsion and preferentially activated a Th2 response $[31,34]$. The cell-mediated immune response induced by SA14-14-2 immunization and NS1 stimulation was also studied. Compared with the NS1 group, the SA14-14-2 group showed higher cell proliferation SI but lower IFN$\gamma$ production. These differences may be due to different epitope presentation from native protein or replicative virus cytokine profiles in response to NS1 and SA14-142 immunization, respectively. IL-2 was detected in

Table 4 Monoclonal antibodies characterization and testing of passive protection

\begin{tabular}{|c|c|c|c|c|c|c|c|}
\hline MAbs & Intracellular $^{a}$ & $\begin{array}{l}\text { Surface } \\
\text { associated }^{b}\end{array}$ & $\begin{array}{l}\text { IFA }^{c} \\
\text { JEV } \\
\text { Dengue } 2 \text { V }\end{array}$ & & $\begin{array}{l}\text { Affinity } \\
\text { KD } \\
(n M)^{d}\end{array}$ & $\begin{array}{l}\text { MAb } \\
\text { binding } \\
\text { domain }^{\text {e }}\end{array}$ & $\begin{array}{l}\% \text { Mice } \\
\text { survival }^{\text {rate }}\end{array}$ \\
\hline $3 \mathrm{E} 10$ & + & + & + & - & 1.1 & unknown & 16 \\
\hline $4 C 4$ & + & + & + & + & 56 & $\mathrm{NS}_{1-143}$ & 33 \\
\hline $7 C 2$ & + & + & + & + & 17 & $\mathrm{NS1}_{224-352}$ & 8 \\
\hline $7 \mathrm{H} 5$ & + & + & + & + & 6.4 & $\mathrm{NS1}_{224-352}$ & 0 \\
\hline $8 \mathrm{~F} 1$ & + & + & + & + & 5 & $\mathrm{NS1}_{224-352}$ & 0 \\
\hline
\end{tabular}

${ }_{\mathrm{a} / \mathrm{b}}$ MAbs were incubated with S2-NS1 ${ }_{1-352}$ cells permeabilized or untreated (intracellular/surface associate) for fluorescence testing by flow cytometry (FACScan).

c Immunofluorescence assay (IFA) for testing monoclonal antibodies reactivity against BHK cells infected with JEV, and C6/36 cells infected with Dengue 2 virus.

d The affinity of MAbs to NS1 tested by surface plasmon resonance (SPR).

e Reactivity of MAbs for S2- NS1 $1_{1-143}$ or $\mathrm{NS}_{1224-352}$ fragments. Cells lysates were tested by Western blotting (WB). "Unknown" means did not react with both of the NS1 fragments or reduced and boiled NS1.

${ }^{f}$ Six to twelve mice were administered with $100 \mu \mathrm{g}$ of 3E10, 4 C4, 7 C2 and 8 F1, respectively, and challenged by JEV SA14. 
A

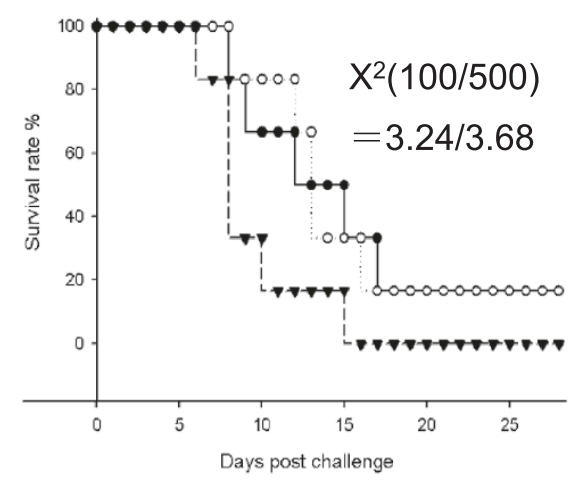

B

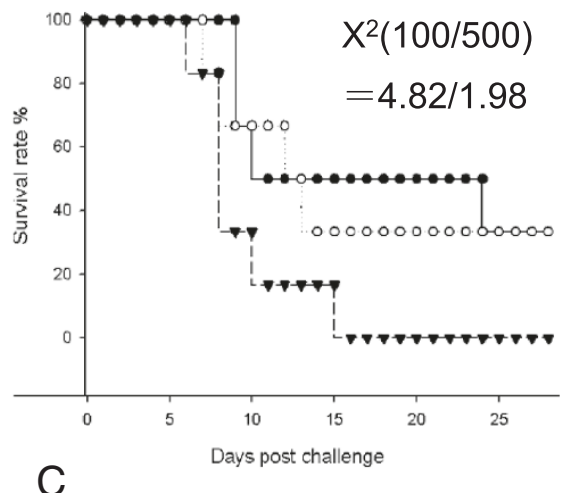

C

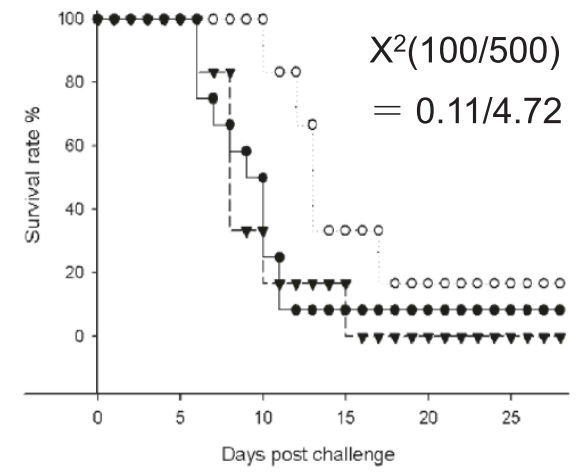

D

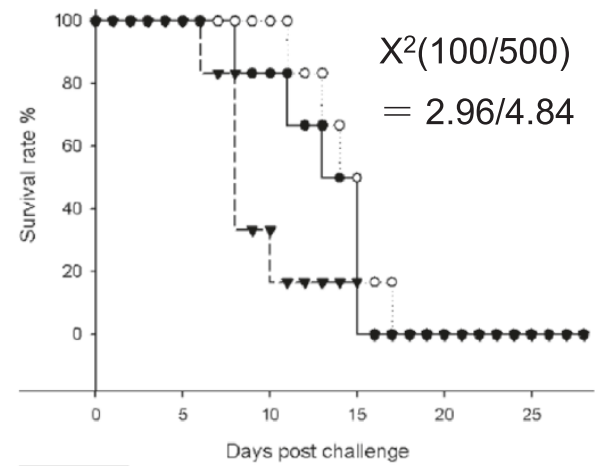

E

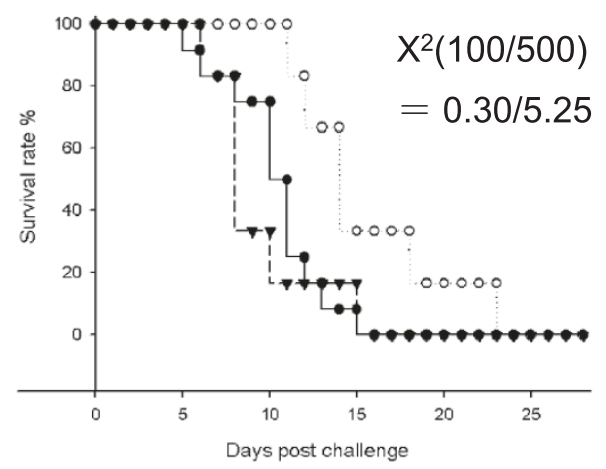

Figure 5 Survival of mice passively immunized with anti-NS1 monoclonal antibodies. Groups of four-week-old C3H mice were administered with $100 \mu \mathrm{g}$ (black dot) or $500 \mu \mathrm{g}$ (white dot) of purified MAbs 3E10 (A), 4C4 (B), 7C2 (C), 7H5 (D), 8F1 (E) before being challenged with 20 pfu of SA14. Another group of mice received $100 \mu \mathrm{g}$ of HIV anti-envelope MAb (black triangle) as a negative control. JEV-infected mice were monitored daily for 28 days post-challenge. Survival curves were constructed using data from one or two experiments with 6-12 mice in each group. $x^{2}$ values were obtained using a log-rank test by comparing the survival curve of each group with the anti-HIV group.

SA14-14-2, but not in NS1-immunized mice (data not shown), confirming a Th1 stimulation pathway induced by replicative viruses. Production of cytotoxic T lymphocytes (CTLs) is another protective immune response induced by NS1 immunogens issued from replicative viruses [35]. Mice primed with JEV-infected cells [36] or JEV NS1 expression recombinant viruses [37] stimulated mice to generate CTLs against JEV. Further study showed that CTLs recognize peptides derived from NS1 and NS3 [35]. One study showed that NS1-expressing DNA immunogen could stimulate CTLs against JEV in mice, but induced low protection [38]. However, we did not expect any CTL response since NS1 was not presented in a replicative system that could stimulate class I antigen presentation.

The protective immune responses elicited against the purified JEV NS1 hexameric protein was investigated by challenging mice with JEV SA14 injected i.n. Immunization 
Table 5 Survival rate of $\mathrm{C} 3 \mathrm{H}$ mice passively immunized with anti-NS1 monoclonal antibodies

\begin{tabular}{llll}
\hline MAbs & \multicolumn{2}{c}{$\begin{array}{c}\text { MAb dose } \\
(\boldsymbol{\mu g})\end{array}$} & $\begin{array}{l}\text { No. of survival mice/ } \\
\text { No. of passive transfer mice (survival rate) }\end{array}$ \\
\hline 3 E10 & 100 & $1 / 6(16.7 \%)$ & 0.07 \\
& 500 & $1 / 6(16.7 \%)$ & 0.05 \\
4 C4 & 100 & $2 / 6(33.3 \%)$ & 0.02 \\
& 500 & $2 / 6(33.3 \%)$ & 0.15 \\
7 C2 & 100 & $1 / 12(8.3 \%)$ & 0.74 \\
& 500 & $1 / 6(16.7 \%)$ & 0.02 \\
7 H5 & 100 & $0 / 6(0 \%)$ & 0.08 \\
& 500 & $0 / 6(0 \%)$ & 0.02 \\
8 F1 & 100 & $0 / 12(0 \%)$ & 0.58 \\
& 500 & $0 / 6(0 \%)$ & 0.02 \\
\multirow{2}{*}{ Anti-HIV 100} & $0 / 6(0 \%)$ & \\
\hline
\end{tabular}

${ }^{a} P$ value was obtained by log rank test when comparing the survival curve of each group of mice which received anti-NS1 MAb with anti-HIV group.

with recombinant subunits required several injections, but the mice were not highly susceptible to JEV at the end of the immunization schedule. However, the i.n. method adopted in this study killed more consistently mice aged over three months than i.p. inoculation (Additional file 2: Figure S2A and B). Another approach would have been to infect mice by an intracerebral or an i.p. route [39], but we felt these techniques did not simulate a natural transmission, as they mechanically break the blood brain barrier. In our study, two doses of $1 \mu \mathrm{g}$ of hexameric NS1 emulsified in adjuvant provided significant protection (83\%) against viral challenge when compared with soluble NS1 (72\%), as it reduced morbidity and mortality and increased the survival period after infection. Anti-NS1 immune responses were induced by YFV, DENV, TBEV and WNV immunization with NS1 protein, an NS1-encoding DNA gene, or viral vectors expressing NS1 $[13,14,18]$. Mouse immunization with JEV NS1 produced in Spodoptera frugiperda Sf9 insect cells induced little or no protection [25], whereas NS1 carried by viral vectors induced an antibody response [26,37], but low protection [26,37]. DNA vaccination of mice with the NS1 gene [40] induced more than $80 \%$ protection, whereas DNA vaccination with the NS1NS2A gene protected only $20 \%$ of mice against a JEV challenge [39]. Interestingly, $100 \mu \mathrm{g}$ of non-folded and nonglycosylated JEV NS1 was produced in E. coli and injected three times to induce protective immunity in $87.5 \%$ of vaccinated mice [32]. Recently, a study using protein E fragments or NS1 produced in E. coli and injected at $50 \mu \mathrm{g}$ seven (i.n.) or five (i.p.) times showed better protection when the proteins were injected i.n. rather than i.p. [41]. Only two much lower doses of the hexameric NS1 form provided protective effects, which may be due to the elicitation of antibodies that bind to conformational epitopes.
Higher antibody titers in the mouse group with a higher survival rate suggested that NS1 had induced an antibody response that might play an important role in preventing JEV infection. In order to verify this hypothesis, different antibody doses induced during mouse immunization were injected into naïve mice. One-month-old mice were used for the adoptive immunity test, so it was possible to apply an i.p. challenge in $\mathrm{C} 3 \mathrm{H}$ mice, which caused 100\% mortality with a low dose of virus [28]. Passive transfer of $100 \mu \mathrm{l}$ of anti-NS1 antisera (titrated 1:3000) to one-month-old mice protected $100 \%$ from morbidity and death, whereas $30 \mu \mathrm{l}$ was less protective and $10 \mu \mathrm{l}$ was not protective, suggesting that an important NS1 function in JEV pathogenesis could be inhibited by IgG-NS1 immunocomplexes. However, anti-NS1 has no neutralizing activity on virus infection in vitro. The antibody-dependent complement-mediated cytolysis of JEV-infected cells associated with anti-NS1 antibodies was demonstrated by in vitro experiments [42]. Another study showed that the depletion of $\mathrm{C} 3$ complement components in mice did not affect the anti-NS1 passive protection capacity against YFV [22]. In addition, immunization with a genetic deletion in C5 using an adenovirus expressing NS1 protected mice from a TBEV lethal challenge [16]. These experiments suggested that antibodydependent complement-mediated cytolysis may play a minor role in antibody-associated immune protection in vivo. However, WNV anti-NS1 MAb through Fc- $\gamma$ receptor-dependent and $\mathrm{C} 1 \mathrm{q}$-independent pathways could be an alternative protection route involving the scavenging of infected cells by macrophages [23,24]. In our study, five JEV anti-NS1 MAbs generated in a previous study [27] that exhibited a high binding affinity against different NS1 epitopes were used in a passive protection test. Two MAbs exhibited no capacity to prevent death, although they significantly extended survival by $2-6$ days. MAb 3E10 was directed against a conformational epitope, while MAb 4C4 recognized the NS1 N-terminus and $7 \mathrm{C} 2$ recognized the NS1 C-terminus and provided significant delay and prevention against JEV mortality. However, $500 \mu \mathrm{g}$ of MAbs 7H5 and 8F1 significantly delayed death after JEV infection in a dose-dependent manner and were probably directed against a linear epitope of the C-terminus fraction of NS1 that cross-reacted with DENV NS1 (Tables 4 and 5). Whether those MAbs recognize the same epitope is not known, but they presented different NS1 binding affinities. Interestingly, anti-WNV MAbs that bound to a similar NS1 fragment also provided mice with up to $90 \%$ protective immunity from a lethal challenge [23]. Identification of the epitope(s) targeted by the three JEV anti-NS1 MAbs would facilitate further study of the NS1 antibody interaction and its function in anti-flaviviral immunity. Further study using a mixture of those MAbs and their possible role in scavenging NS1-IgG complexes would bring a better understanding of the function of anti-NS1 antibodies in protective immunity. 
The mechanism by which NS1 contributes to in vivo flaviviral pathogenesis is largely unknown, which hinders the elucidation of the mechanism whereby anti-NS1 provides protective activity. Anti-NS1 antibodies interact with protein $\mathrm{NS1}^{\prime}$, an elongated form of NS1 found in flaviviruses of the JEV serogroup [43], which is involved in neuroinvasion by WNV subtype Kunjin [44]. However, the mechanism involved remains unknown. It is likely that, in addition to interacting with NS1, anti-NS1 antibodies may block the in vivo deleterious activity of NS1' in WNV and JEV infections. Understanding this interaction would open up new research avenues.

NS1 alone cannot induce a sterilizing immunity, but it contributes to the consolidation of flavivirus neutralizing immunity that is primarily elicited by protein E. Several vaccine candidates are known to provide better protection when NS1 is included in the vaccine preparation $[38,45-$ 50]. A recent study demonstrated the enhancement of anti$\mathrm{E}$ antibody neutralization titer by mouse co-immunization of protein E with NS1, suggesting that NS1 might be usefully added to the viral structural components in a JEV vaccine [51].

A previous study showed that autoantibodies induced by DENV NS1 recognized coagulation factors including fibrinogen and platelets, as well as integrin/adhesion proteins [8]. Binding of anti-DENV NS1 antibodies to endothelial cells induced inflammation and apoptosis [10]. The possibility that other flaviviral NS1 proteins may elicit autoantibodies when used as components of a vaccine should not be underestimated. Whether JEV NS1 induced autoantibodies needs further study. However, JEV anti-NS1 antibodies did not bind to endothelial cells like DENV anti-NS1 antibodies did [10] and JEV infection does not cause hemorrhagic manifestations, minimizing the role of NS1-elicited autoantibodies.

In summary, immunization with a hexameric NS1 elicited Th2 and low Th1 cell responses, and induced a partial protective immune response in a mouse model. The ISA-51-VG adjuvant improved the performance of NS1 immunization by contributing to the production of higher antibody titers and increased the mouse survival rate. Passive transfer of sufficient anti-NS1 antibodies provided full protection to mice from lethal JEV challenge. However, anti-NS1 MAbs provided poor protection, although they significantly extended the survival period before death. These results support the hypothesis that anti-NS1 antibodies participate in immune protection against JEV infection.

\section{Materials and Methods}

\section{Cells and viruses}

Baby hamster kidney (BHK-21) cell lines were cultured in Dulbecco's modified Eagle's medium (DMEM, Invitrogen, Carlsbad, CA, USA) containing 3\% fetal bovine serum (FBS), $100 \mathrm{U}$ penicillin, and $100 \mu \mathrm{g}$ streptomycin at $37{ }^{\circ} \mathrm{C}$ in $5 \% \mathrm{CO}_{2}$. The JEV SA14 strain was obtained from the National Institute for the Control of Pharmaceutical and Biological Products (Beijing, China). The attenuated vaccine strain JEV SA14-14-2 was obtained from the Chengdu Institute of Biological Products (Chengdu, China). BHK-21 cells were infected at a multiplicity of infection of 0.1 pfu cell ${ }^{-1}$. Drosophila S2 cells were purchased from Invitrogen (Carlsbad, CA, USA) and cultured in Schneider's Drosophila medium (Invitrogen) with 10\% FBS, $50 \mathrm{U}$ penicillin, and $50 \mu \mathrm{g}$ streptomycin, and incubated at $28{ }^{\circ} \mathrm{C}$.

\section{NS1 expression and purification from Drosophila S2 cells}

NS1 protein expression and purification procedures were conducted according to previously published methods [27]. Briefly, the JEV Nakayama strain genes encoding the full-length 352 amino acids of NS1 and its fragments, containing N-terminus amino acids (1-143) and Cterminus amino acids (224-352), were amplified by RTPCR and inserted into the pMT/Bip/V5-His A plasmid vector to produce pMT-NS1 $1_{1-352}, \mathrm{pMT}-\mathrm{NS} 1_{1-143}$, and pMT-NS1 $1_{224-352}$, respectively. Drosophila S2 cells were cotransfected with plasmids pMT-NS1 $1_{1-352}, \mathrm{pMT}_{-\mathrm{NS}} 1_{1-143}$, or pMT-NS1 $224-352$, and pCoblast (Invitrogen). S2 cells were selected using blasticidin. To improve NS1 production, cell populations were cloned by limit dilution to generate an S2-NS1 cell clone expressing high levels of NS1. Cells were cultured in Express Five medium (Invitrogen) without FBS in a Wave Bioreactor ${ }^{\mathrm{Tm}}$ (GE Amersham, Uppsala, Sweden). Cell supernatants were collected, filtered, and concentrated, and the buffer was exchanged. The resultant fluids containing NS1 were loaded onto a chelating sepharose column (GE Amersham). The column was washed with binding buffer and the recombinant protein was eluted. After nickel ion column chromatography, the protein was applied to a size exclusion Superdex 200 10/300 column using the AKTA Purifier System (GE Amersham).

\section{Carbohydrate analysis of JEV NS1 secreted from Drosophila S2-NS1 cell clone}

The NS1 denatured monomeric form was digested by Endoglycosidase $\mathrm{H}$ (Endo $\mathrm{H}$ ) or Peptide: $\mathrm{N}$-glycosidase $\mathrm{F}$ (PNGase F) (New England BioLabs, Beverley, MA, USA) according to the manufacturer's instruction. Briefly, $3 \mu \mathrm{g}$ of native or denatured NS1 were mixed with 6,000 units of Endo $\mathrm{H}$ or 7,000 units of PNGase $\mathrm{F}$ in reaction buffer, and incubated at $37{ }^{\circ} \mathrm{C}$ for $3 \mathrm{hr}$. After digestion, the reaction mixtures were added to equal volumes of 2 times loading buffer, heated at $95{ }^{\circ} \mathrm{C}$ for $5 \mathrm{~min}$, and separated by $12.5 \%$ SDS-polyacrylamide gel electrophoresis (SDSPAGE).

Glycosylation differentiation: The DIG glycan differentiation kit (Roche, Mannheim, Germany) was used for 
NS1 glycan differentiation. The NS1 proteins and control glycoproteins were transferred onto nitrocellulose membranes after gel electrophoretic separation. The membranes were incubated in blocking buffer for $1 \mathrm{hr}$, washed twice in TBS (Tris buffered saline) and once in buffer 1 (TBS; $1 \mathrm{mM} \mathrm{MgCl} 2,1 \mathrm{mM} \mathrm{MnCl} 2,1 \mathrm{mM}$ $\mathrm{CaCl} 2, \mathrm{pH}$ 7.5) and incubated each $1 \mathrm{hr}$ with digoxigenin-labeled GNA, SNA, MAA, and DSA. The membranes were washed three times with TBS, then anti-digoxigenin-alkaline phosphatase was added and incubated for $1 \mathrm{hr}$. The membranes were washed three times in distilled water and $1 \mathrm{ml}$ of alkaline phosphatase substrate (Promega, San Luis Obispo, CA, USA) was added to each membrane for staining.

\section{Western blotting}

The NS1 protein sample was boiled at $95{ }^{\circ} \mathrm{C}$ for $5 \mathrm{~min}$ in a reducing SDS loading buffer, then separated by $10 \%$ SDS-PAGE. The protein was transferred to nitrocellulose membranes that were blocked with $5 \%$ non-fat milk in TBS/Tween-20 before being incubated with a 1:1000 dilution of anti-V5 tag or anti-NS1 MAbs. After washing, the membranes were incubated with a 1:3000 dilution of alkaline-phosphatase-conjugated secondary antibodies (Promega). Signals were detected based on the coloration of an alkaline phosphatase dark blue substrate (Promega).

\section{Antibody titration}

The anti-NS1 antibody titers were tested by ELISA. One hundred ng per well of purified NS1 protein was coated onto 96-well plates (Corning Costar, Lowell, MA, USA) that were incubated overnight at $4^{\circ} \mathrm{C}$. Plates were washed and blocked with PBS/3\% BSA. A series of 1:2 dilutions (from 1:100 to $1: 204,800$ in $\mathrm{PBS} / 1 \%$ BSA) of mouse serum was added to the wells and incubated for $1 \mathrm{~h}$ at room temperature (RT). Plates were washed before adding horseradish-peroxidase-labeled goat antimouse IgG $(\mathrm{H}+\mathrm{L})$, IgG1, IgG2a, (Southern Biotech, Birmingham, AL, USA) that were diluted 5,000-fold. Plates were then incubated for $1 \mathrm{~h}$ at RT. The plates were washed again before adding ortho-phenyl diamine substrate (Sigma-Aldrich) and incubated for $10 \mathrm{~min}$ at RT. Enzymatic reactions were stopped with $3 \mathrm{M} \mathrm{H}_{2} \mathrm{SO} 4$ and absorbance was recorded at $492 \mathrm{~nm}$ using an ELISA plate reader (Molecular Devices, Sunnyvale, CA, USA)

Neutralizing antibody titers were determined in BHK cells. Pooled sera from each group were subjected to two fold dilutions in DMEM 2\% FBS from 1:20 to 1:320 dilution, and mixed with $150 \mathrm{pfu}$ (corresponding to 10 $\mathrm{TCID}_{50}$ ) of JEV SA14 virus in 96-well plates before incubating for $1 \mathrm{~h}$ at $37^{\circ} \mathrm{C}$, after which 6,000 BHK cells were added. The plates were read after $3 \mathrm{~d}$, and the serum dilution that reduced $50 \%$ of the virus $\left(\mathrm{TCID}_{50}\right)$ was recorded.

\section{Lymphocyte proliferation and IFN- $\gamma$ secretion}

Two weeks after the 2nd inoculation of NS1, PBS, or six weeks after the inoculation of SA14-14-2, DMEM with 3\% FBS (complete DMEM medium), three mice were killed from each group. Mouse spleens were isolated and crushed in cell strainers (Becton, Dickinson and Company, Franklin Lakes, NY, USA) to prepare splenocyte suspensions. Erythrocytes were lysed with red blood cell lysis solution $\left(15.5 \mathrm{mM} \mathrm{NH} \mathrm{m}_{4} \mathrm{Cl}, 1 \mathrm{mM} \mathrm{KHCO}_{3}\right.$, and $0.01 \mathrm{mM}$ EDTA-2Na) and centrifuged at $500 \times \mathrm{g}$, for five min, the cell pellet was washed three times then resuspended in cell culture medium. The cell concentration of each mouse was counted and diluted to $4 \times 10^{6}$ cells $\mathrm{ml}^{-1}$ in RPMI 1640 medium with $10 \%$ heatinactivated FBS to be used for lymphocyte proliferation and cytokine production assays [52]. Mouse splenocytes were cultured with $5 \mu \mathrm{g} \mathrm{ml}^{-1}$ of JEV NS1 protein. T-cell proliferation was quantified using the Cell Titer $96^{\circledR}$ Aqueous Non-Radioactive Cell Proliferation Assay (Promega), according to the manufacturer's instructions. Tlymphocyte proliferation was measured using a stimulation index, which was expressed as the $\mathrm{OD}_{570}$ ratio of NS1-stimulated wells to that of wells without NS1 [53].

Splenocyte suspensions $(0.5 \mathrm{ml})$ were dispensed into the wells of a 24-well cell culture plate. An equal volume of NS1 $\left(10 \mu \mathrm{g} \mathrm{ml}^{-1}\right)$ in medium was also added. Cells were incubated for $5 \mathrm{~d}$. Cell culture supernatants were harvested and stored at $-80^{\circ} \mathrm{C}$ before analysis. IFN- $\gamma$ production was tested using a Mouse IFN- $\gamma$ ELISA Kit (BD Pharmingen, San Diego, CA, USA), according to the manufacturers' instructions [52].

\section{Anti-NS1 MAb preparation and characterization}

Anti-JEV MAb preparation followed a previously published method [27]. Briefly, MAbs were purified from hybridoma cultured supernatants or from mouse ascitic fluid using Protein A or Protein G columns (GE Amersham). Antibodies were characterized by flow cytometry to determine cell surface and intracellular NS1 recognition. Epitope mapping was performed using an ELISA or Western blotting with full-length, and $\mathrm{N}$-terminus (amino acids 1-143) and C-terminus (amino acids 224352) NS1 fragments [27].

\section{Mouse immunization and challenge}

The mouse experimental protocol was approved by the Institut Pasteur of Shanghai Ethics Committee for Animal Care (ID\# 01-2006) and was conducted in the Institut Pasteur animal facility following the European directive 2010/63/EU on the protection of animals used for scientific purposes. 
Four-week-old female $\mathrm{C} 3 \mathrm{H} / \mathrm{HeN}$ mice were purchased from Vital River, the Chinese representative of Charles River Laboratories (Vital River Lab Animal Technology Co., Ltd, Beijing, China). Mice were separated into four groups: a negative control group that received $200 \mu \mathrm{l}$ of PBS i.p.; a positive control group that received one dose of $10^{4} \mathrm{pfu}$ JEV SA14-14-2 vaccine i.p.; an NS1 group that was injected with $1 \mu \mathrm{g}$ of NS1 in $200 \mu \mathrm{l}$ of PBS (aqueous NS1); and a group injected with $1 \mu \mathrm{g}$ of NS1 emulsified with water-in-oil adjuvant by mixing NS1 in $100 \mu \mathrm{l}$ of PBS with an equal volume of Montanide oil (ISA-51-VG, SEPPIC SA, Puteaux, France) in a latex-free syringe. All groups were immunized by the $\mathrm{i}$. p. route with two doses of antigen four weeks apart. Mouse sera were collected two weeks after the second inoculation. Four weeks after the second inoculation, mice were transferred in isolators to a biosafety level 2 animal facility, where they were challenged by i.n. inoculation of $10 \mu \mathrm{l}$ containing $10^{4} \mathrm{pfu}$ of SA14 virus in each nostril. Surviving mice sera were collected for antibody titration.

\section{Mouse passive protection}

Four-week-old mice were treated by i.p. transfer of $100 \mu$ l, $30 \mu \mathrm{l}, 10 \mu \mathrm{l}$ of pooled anti-NS1 mouse sera obtained from NS1-immunized mice containing an anti-NS1 antibody titer $>1: 3000$, or $100 \mu \mathrm{g}$ or $500 \mu \mathrm{g}$ of anti-NS1 MAbs. An HIV anti-envelop IgG1 MAb (a generous gift from Pr. Paul Zhou, Institut Pasteur of Shanghai) was used as an isotype control. Passive transfer of pooled anti-JEV antisera obtained from mice vaccinated with SA14-14-2 was used as a positive control. All sera were pre-incubated at $56^{\circ} \mathrm{C}$ for $30 \mathrm{~min}$. One hour after the sera injection, mice were challenged with an injection of 20 pfu of JEV SA14. Mouse survival rates were calculated four weeks after the challenge.

\section{Statistics}

Cell proliferation, cytokine, and antibody titer data were analyzed by Excel and expressed as the mean \pm SD. Survival analysis curves were analyzed using the log-rank test calculated by STATA version 11.1 (StataCorp, College Station, TX, USA). Figures were created using Sigmaplot (Systat Software, Inc., San Jose, CA, USA).

\section{Additional Files}

Additional file 1: Figure S1. Characterization of carbohydrates of S2 cells expressing NS1. A: Purified NS1 protein was denatured and mocktreated (lane 1) or incubated with Endo H (lane 2) and PNGase F (lane 3) and the products were separated by SDS-PAGE. B: After electrophoresis, the GNA recognition control glycoprotein carboxypeptidase Y (arrow, lane 1), the DSA recognition control glycoprotein asialofetuin (lane 3), and NS1 protein (arrows, lanes 2 and 4) were transferred to a nitrocellulose membrane and incubated with digoxigenin-labeled GNA (lanes 1 and 2) or DSA (lanes 3 and 4) and further incubated with antidigoxigenin alkaline phosphatase-labeled antibodies and with alkaline phosphatase substrate.
Additional file 2: Figure S2. Susceptibility of $\mathrm{C} 3 \mathrm{H}$ mice to JEV SA14 infection. Groups of six $\mathrm{C} 3 \mathrm{H}$ mice infected with JEV SA 14 were monitored daily for 28 days. Two groups of three-month-old $\mathrm{C} 3 \mathrm{H}$ mice were infected with different doses of JEV SA14 by intraperitoneal (A) or intranasal (B) route. One group of one-month-old $\mathrm{C} 3 \mathrm{H}$ mice was infected with different doses of JEV SA14 by intraperitoneal route (C).

\section{Competing interests}

The authors declare that they have no competing interests.

\section{Acknowledgments}

We wish to thank the Chengdu Institute of Biological Products (Chengdu, China) for sharing the JEV vaccine SA14-14-2. The JEV SA14 was obtained from the National Institute for the Control of Pharmaceutical and Biological Products, Beijing, China. We thank Mr Regis Vialle (SEPPIC SA) for providing ISA-51-VG adjuvant used in this study. We thank Pr. Paul Zhou (Institut Pasteur of Shanghai-Chinese Academy of Sciences) for providing anti-HIV MAb. We thank Prs. Ralf Altmeyer and Bing Sun for their interest and support of this study. D.C. was a recipient of an award from the Areva Foundation. This study was supported by the Shanghai Pasteur Health Research Foundation.

\section{Author details}

${ }^{1}$ Key Laboratory of Molecular Virology and Immunology, Institut Pasteur of Shanghai, Shanghai Institutes for Biological Sciences, Chinese Academy of Sciences, Shanghai 20025, China. ${ }^{2}$ Unit of Virology, Institut Pasteur in Cambodia, Phnom Penh, Cambodia. ${ }^{3}$ National Institute for the Control of Pharmaceutical and Biological Products, Tiantan Xili Chongwen Qu, Beijing 100050, China. ${ }^{4}$ Present address: Institut Pasteur in Cambodia, Phnom Penh, Cambodia.

\section{Authors' contributions}

Conception of the study and design of the experiments: YL, VDe. Performance of the experiments: YL, CD, LP. Advice and assistance with the live-attenuated vaccine JEV: YY. Analysis of the data and statistics: YL, VDe, VDu. Writing of the paper: YL, VDe. All authors read and approved the final manuscript.

Received: 17 September 2011 Accepted: 24 July 2012

Published: 24 July 2012

\section{References}

1. Mackenzie JS: Emerging zoonotic encephalitis viruses: lessons from Southeast Asia and Oceania. J Neurovirol 2005, 11:434-440.

2. Chambers TJ, Hahn CS, Galler R, Rice CM: Flavivirus genome organization, expression, and replication. Annu Rev Microbiol 1990, 44:649-688.

3. Lindenbach BD, Rice CM: Genetic interaction of flavivirus nonstructural proteins NS1 and NS4A as a determinant of replicase function. J Virol 1999, 73:4611-4621.

4. Gutsche I, Coulibaly F, Voss JE, Salmon J, D'Alayer J, Ermonval M, Larquet E, Charneau P, Krey T, Megret F, et al: Secreted dengue virus nonstructural protein NS1 is an atypical barrel-shaped high-density lipoprotein. Proc Natl Acad Sci USA 2011, 108:8003-8008.

5. Chung KM, Liszewski MK, Nybakken G, Davis AE, Townsend RR, Fremont DH, Atkinson JP, Diamond MS: West Nile virus nonstructural protein NS1 inhibits complement activation by binding the regulatory protein factor H. Proc Natl Acad Sci USA 2006, 103:19111-19116.

6. Avirutnan P, Fuchs A, Hauhart RE, Somnuke P, Youn S, Diamond MS, Atkinson JP: Antagonism of the complement component C 4 by flavivirus nonstructural protein NS1. J Exp Med 2010, 207:793-806.

7. Avirutnan P, Hauhart RE, Somnuke P, Blom AM, Diamond MS, Atkinson JP: Binding of flavivirus nonstructural protein NS1 to C4b binding protein modulates complement activation. J Immunol 2011, 187:424-433.

8. Falconar AKI: The dengue virus nonstructural-1 protein (NS1) generates antibodies to common epitopes on human blood clotting, integrin/ adhesin proteins and binds to human endothelial cells: potential implications in haemorrhagic fever pathogenesis. Arch Virol 1997, 142:897-916.

9. Chang HH, Shyu HF, Wang YM, Sun DS, Shyu RH, Tang SS, Huang YS: Facilitation of cell adhesion by immobilized dengue viral nonstructural 
protein 1 (NS1): arginine-glycine-aspartic acid structural mimicry within the dengue viral NS1 antigen. J Infect Dis 2002, 186:743-751.

10. Lin CF, Lei HY, Shiau AL, Liu HS, Yeh TM, Chen SH, Liu CC, Chiu SC, Lin YS: Endothelial cell apoptosis induced by antibodies against dengue virus nonstructural protein 1 via production of nitric oxide. J Immunol 2002, 169:657-664.

11. Jelinek T: Ixiaro: a new vaccine against Japanese encephalitis. Expert Rev Vaccines 2009, 8:1501-1511

12. Hills SL, Griggs AC, Fischer M: Japanese encephalitis in travelers from nonendemic countries, 1973-2008. Am J Trop Med Hyg 2010, 82:930-936.

13. Schlesinger JJ, Brandriss MW, Cropp CB, Monath TP: Protection against yellow fever in monkeys by immunization with yellow fever virus nonstructural protein NS1. J Virol 1986, 60:1153-1155.

14. Falgout B, Bray M, Schlesinger JJ, Lai CJ: Immunization of mice with recombinant vaccinia virus expressing authentic dengue virus nonstructural protein NS1 protects against lethal Dengue virus encephalitis. J Virol 1990, 64:4356-4363.

15. Putnak JR, Schlesinger JJ: Protection of mice against yellow fever virus encephalitis by immunization with a vaccinia virus recombinant encoding the yellow fever virus nonstructural proteins, NS1, NS2a and NS2b. J Gen Virol 1990, 71:1697-1702.

16. Jacobs SC, Stephenson JR, Wilkinson GWG: Protection elicited by a replication-defective adenovirus vector expressing the tick-borne encephalitis virus nonstructural glycoprotein NS1. J Gen Virol 1994 75:2399-2402.

17. Timofeev AV, Ozherelkov SV, Pronin AV, Deeva AV, Karganova GG, Elbert LB, Stephenson JR: Immunological basis for protection in a murine model of tick-borne encephalitis by a recombinant adenovirus carrying the gene encoding the NS1 non-structural protein. J Gen Virol 1998, 79(Pt 4): 689-695.

18. Schepp-Berglind J, Luo M, Wang D, Wicker JA, Raja NU, Hoel BD, Holman $\mathrm{DH}$, Barrett AD, Dong JY: Complex adenovirus-mediated expression of West Nile virus C, PreM, E, and NS1 proteins induces both humoral and cellular immune responses. Clin Vaccine Immunol 2007, 14:1117-1126.

19. Wu SF, Liao CL, Lin YL, Yeh CT, Chen LK, Huang YF, Chou HY, Huang J, Shaio MF, Sytwu HK: Evaluation of protective efficacy and immune mechanisms of using a non-structural protein NS1 in DNA vaccine against dengue 2 virus in mice. Vaccine 2003, 21:3919-3929.

20. Timofeev AV, Butenko VM, Stephenson JR: Genetic vaccination of mice with plasmids encoding the NS1 non-structural protein from tick-borne encephalitis virus and dengue 2 virus. Virus Genes 2004, 28:85-97.

21. Henchal EA, Henchal LS, Schlesinger JJ: Synergistic interactions of anti-NS1 monoclonal-antibodies protect passively immunized mice from lethal challenge with dengue-2 virus. J Gen Virol 1988, 69:2101-2107.

22. Schlesinger JJ, Foltzer M, Chapman S: The Fc portion of antibody to yellow fever virus NS1 is a determinant of protection against YF encephalitis in mice. Virology 1993, 192:132-141.

23. Chung KM, Nybakken GE, Thompson BS, Engle MJ, Marri A, Fremont DH, Diamond MS: Antibodies against West Nile virus nonstructural protein NS1 prevent lethal infection through Fc gamma receptor-dependent and -independent mechanisms. J Virol 2006, 80:1340-1351.

24. Chung KM, Thompson BS, Fremont DH, Diamond MS: Antibody recognition of cell surface-associated NS1 triggers Fc-gamma receptormediated phagocytosis and clearance of West Nile virus-infected cells. $J$ Virol 2007, 81:9551-9555

25. McCown J, Cochran M, Putnak R, Feighny R, Burrous J, Henchal E, Hoke C: Protection of mice against lethal Japanese encephalitis with a recombinant baculovirus vaccine. Am J Trop Med Hyg 1990, 42:491-499.

26. Konishi E, Pincus S, Fonseca BAL, Shope RE, Paoletti E, Mason PW: Comparison of protective immunity elicited by recombinant vaccinia viruses that synthesize E or NS1 of Japanese encephalitis virus. Virology 1991, 185:401-410.

27. Li YZ, Counor D, Lu P, Liang GD, Huong VT, Nga PT, Loan HT, Sun G, Grandadam M, Butrapet $S$, et al: A specific and sensitive antigen capture assay for NS1 protein quantitation in Japanese encephalitis virus infection. J Virol Methods 2011, 179:8-16.

28. Wang K, Deubel V: Mice with different susceptibility to Japanese encephalitis virus infection show selective neutralizing antibody response and myeloid cell infectivity. PLoS One 2011, 6:e24744.

29. Modis Y, Ogata S, Clements D, Harrison SC: Structure of the dengue virus envelope protein after membrane fusion. Nature 2004, 427:313-319.
30. Abbas AK, Murphy KM, Sher A: Functional diversity of helper $\mathrm{T}$ lymphocytes. Nature 1996, 383:787-793.

31. Aucouturier J, Dupuis L, Deville S, Ascarateil S, Ganne V: Montanide ISA 720 and 51: a new generation of water in oil emulsions as adjuvants for human vaccines. Expert Rev Vaccines 2002, 1:111-118.

32. Lin CW, Liu KT, Huang HD, Chen WJ: Protective immunity of Ecolisynthesized NS1 protein of Japanese encephalitis virus. Biotechnol Lett 2008, 30:205-214.

33. Alcon-LePoder S, Drouet MT, Roux P, Frenkiel MP, Arborio M, DurandSchneider AM, Maurice M, Le Blanc I, Gruenberg J, Flamand M: The secreted form of dengue virus nonstructural protein NS1 is endocytosed by hepatocytes and accumulates in late endosomes: implications for viral infectivity. J Virol 2005, 79:11403-11411.

34. Goel N, Rong Q, Zimmerman D, Rosenthal KS: A L.E.A.P.S. ${ }^{\text {TM }}$ heteroconjugate vaccine containing a T cell epitope from HSV-1 glycoprotein D elicits Th1 responses and protection. Vaccine 2003, 21:4410-4420.

35. Murali-Krishna K, Ramireddy B, Ravi V, Manjunath R: Recognition of nonstructural protein-peptides by cytotoxic $T$ lymphocytes raised against Japanese encephalitis virus. Microbiol Immunol 1995, 39:10211024

36. Murali-Krishna K, Ravi V, Manjunath R: Japanese encephalitis virus infection of mouse cell lines: ability to prime mice for generation of virus-specific cytotoxic T lymphocytes and differences in CTL recognizable viral determinants. Arch Virol 1995, 140:127-143.

37. Xu G, Xu X, Li Z, He Q, Wu B, Sun S, Chen H: Construction of recombinant pseudorabies virus expressing NS1 protein of Japanese encephalitis (SA14-14-2) virus and its safety and immunogenicity. Vaccine 2004, 22:1846-1853.

38. Konishi E, Ajiro N, Nukuzuma C, Mason PW, Kurane I: Comparison of protective efficacies of plasmid DNAs encoding Japanese encephalitis virus proteins that induce neutralizing antibody or cytotoxic $T$ lymphocytes in mice. Vaccine 2003, 21:3675-3683

39. Chen HW, Pan CH, Liau MY, Jou R, Tsai CJ, Wu HJ, Lin YL, Tao MH: Screening of protective antigens of Japanese encephalitis virus by DNA immunization: a comparative study with conventional viral vaccines. J Virol 1999, 73:10137-10145.

40. Lin YL, Chen LK, Liao CL, Yeh CT, Ma SH, Chen JL, Huang YL, Chen SS, Chiang HY: DNA immunization with Japanese encephalitis virus nonstructural protein NS1 elicits protective immunity in mice. $J$ Virol 1998, 72:191-200.

41. Tafuku S, Miyata T, Tadano M, Mitsumata R, Kawakami H, Harakuni T, Sewaki T, Arakawa T: Japanese encephalitis virus structural and nonstructural proteins expressed in Escherichia coli induce protective immunity in mice. Microbes Infect 2012, 14:169-176.

42. Krishna VD, Rangappa M, Satchidanandam V: Virus-specific cytolytic antibodies to nonstructural protein 1 of Japanese encephalitis virus effect reduction of virus output from infected cells. J Virol 2009, 83:4766-4777.

43. Firth $A E$, Atkins JF: A conserved predicted pseudoknot in the NS2Aencoding sequence of West Nile and Japanese encephalitis flaviviruses suggests NS1' may derive from ribosomal frameshifting. Virol J 2009, 6:14.

44. Melian EB, Hinzman E, Nagasaki T, Firth AE, Wills NM, Nouwens AS, Blitvich BJ, Leung J, Funk A, Atkins JF, et al: NS1' of flaviviruses in the Japanese encephalitis virus serogroup is a product of ribosomal frameshifting and plays a role in viral neuroinvasiveness. J Virol 2010, 84:1641-1647.

45. Zhang YM, Hayes EP, McCarty TC, Dubois DR, Summers PL, Eckels KH, Chanock RM, Lai CJ: Immunization of mice with dengue structural proteins and nonstructural protein NS1 expressed by baculovirus recombinant induces resistance to dengue virus encephalitis. $J$ Virol 1988, 62:3027-3031.

46. Bray M, Zhao BT, Markoff L, Eckels KH, Chanock RM, Lai CJ: Mice immunized with recombinant vaccinia virus expressing dengue-4 virus structural proteins with or without nonstructural protein-NS1 are protected against fatal dengue virus encephalitis. J Virol 1989, 63:2853-2856.

47. Eckels KH, Dubois DR, Summers PL, Schlesinger JJ, Shelly M, Cohen S, Zhang YM, Lai CJ, Kurane I, Rothman A, et al: Immunization of monkeys with baculovirus-dengue type-4 recombinants containing envelope and nonstructural proteins: evidence of priming and partial protection. Am J Trop Med Hyg 1994, 50:472-478.

48. Hall RA, Nisbet DJ, Pham KB, Pyke AT, Smith GA, Khromykh AA: DNA vaccine coding for the full-length infectious Kunjin virus RNA protects 
mice against the New York strain of West Nile virus. Proc Natl Acad Sci USA 2003, 100:10460-10464.

49. Yang DK, Kweon CH, Kim BH, Lim Sl, Kwon JH, Kim SH, Song JY, Han HR: Immunogenicity of baculovirus expressed recombinant proteins of Japanese encephalitis virus in mice. J Vet Sci 2005, 6:125-133.

50. Watts DM, Tesh RB, Siirin M, Rosa AT, Newman PC, Clements DE, Ogata S, Coller BA, Weeks-Levy C, Lieberman MM: Efficacy and durability of a recombinant subunit West Nile vaccine candidate in protecting hamsters from West Nile encephalitis. Vaccine 2007, 25:2913-2918.

51. Ishikawa T, Wang G, Widman DG, Infante E, Winkelmann ER, Bourne N, Mason PW: Enhancing the utility of a prM/E-expressing chimeric vaccine for Japanese encephalitis by addition of the JEV NS1 gene. Vaccine 2011 29:7444-7455.

52. Lieberman MM, Clements DE, Ogata S, Wang G, Corpuz G, Wong T, Martyak T, Gilson L, Coller BA, Leung J, et al: Preparation and immunogenic properties of a recombinant West Nile subunit vaccine. Vaccine 2007, 25:414-423.

53. Chu JH, Chiang CC, Ng ML: Immunization of flavivirus West Nile recombinant envelope domain III protein induced specific immune response and protection against West Nile virus infection. J Immunol 2007, 178:2699-2705.

doi:10.1186/1743-422X-9-135

Cite this article as: Li et al:: Protective immunity to Japanese encephalitis virus associated with anti-NS1 antibodies in a mouse model. Virology Journal 2012 9:135.

\section{Submit your next manuscript to BioMed Central and take full advantage of:}

- Convenient online submission

- Thorough peer review

- No space constraints or color figure charges

- Immediate publication on acceptance

- Inclusion in PubMed, CAS, Scopus and Google Scholar

- Research which is freely available for redistribution 